\title{
WHO YOU ARE AND HOW YOU WORK: EMBEDding PoSiTIONALITY IN ENGINEERING DESIGN
}

\author{
Noosheen Walji ${ }^{1}$, Patricia K. Sheridan ${ }^{2,3}$, Penny Kinnear ${ }^{3,4}$, Robert Irish ${ }^{3,4}$, and Jason Foster ${ }^{5}$ \\ ${ }^{1}$ Dept. of Mechanical and Industrial Engineering, ${ }^{2}$ Institute for Leadership Education in Engineering, \\ ${ }^{3}$ Institute for Studies in Transdisciplinary Engineering Education and Practice, ${ }^{4}$ Engineering Communication Program, \\ ${ }^{5}$ Division of Engineering Science \\ University of Toronto \\ noosheen.walji@mail.utoronto.ca,patricia.sheridan@utoronto.ca
}

\begin{abstract}
As the Engineering profession increasingly explores the complex relationships between technology and society, the responsibility of engineers is evolving to include considering the socio-technical complexities in which their technology will be embedded [1]. This evolution has led to interest in teaching empathy and reflexivity in undergraduate engineering education, in part to prepare student engineers for effective community engagement in their engineering practice [2] [3].

This practice paper discusses considerations, approaches, and theories that informed our design practice as we incorporated positionality into our course. Positionality was introduced as a foundational design tool to approximately 300 students in a first-year design course at a large, public, research-intensive university. In this work we discuss the integration of positionality as a framework to facilitate self-awareness, intentionality, leadership, reflexivity, and empathy in individual and team engineering design activities.
\end{abstract}

Keywords: Positionality, undergraduate engineering education, first-year engineering design, engineering leadership, reflexivity, course design, assignment design

\section{INTRODUCTION}

This practice paper discusses considerations, approaches, and theories that informed our design practice to incorporate positionality into a first-year engineering design course. Linda Alcoff defines positionality as the social and political position of an individual determined by their race, class, gender, sexuality, and ability [1]. While positionality generally asks how who we are influences what we know about the world [2], in the design education context we ask how who we are informs how we perceive and address an engineering design opportunity. We apply the concept of positionality in the framing stage of an engineering design activity, as a tool to elicit the values and biases that student engineers bring to their work, and as a strategy to better understand and interpret stakeholders. In this context, exploring the positionality of oneself and others becomes a means of developing empathy and engaging in reflexivity during the early phases of an engineering design activity.

This paper is presented as a starting point, to share the background on positionality in the literature, how leadership, equity, diversity and inclusion can be embedded into engineering design practice. Research and findings about student responsiveness to the concepts and approach will be shared in subsequent articles.

\section{LITERATURE REVIEW}

In the literature, concepts of positionality and reflexivity grew as a means of addressing the emergence of post-structuralist approaches in feminist theory and social psychology research. Early discussions of positionality addressed research methods that could facilitate an understanding of the researcher, the researched, and the research context, though with recognition of the challenges involved in applying these methods [1] [2] [3]. Since then, positionality has been applied as a tool to better understand and incorporate the complexity of human behaviour in multiple contexts. For example, Kezar explores the relationship between one's positionality and their leadership beliefs [4].

By the 2000's, education research introduced a number of frameworks for considering positionality [5], applying positionality to inform changes to teaching methods and curriculum [6], and enhancing learning with examples of classroom activities to teach positionality in higher education [7] [8]. In his examination of positionality in the classroom, Takacs found that having students explore how their positionally influences their epistemology fostered improvements in analytical thinking and communication while creating space for a more nuanced and scholarly discussion about society [9].

Even though engineering has become more interdisciplinary, positionality has not been well explored in the field. A related concept, reflexivity, has been introduced as an essential skill in engineering practice, 
with the goal of developing an adaptable and integrated understanding of socio-technical systems [10] [11]. However, reflexivity is merely a technique to examine or explore positionality. Walther et al. [12], have introduced positionality in engineering in the form of applying empathy to engineering design to more thoughtfully engage with socio-technical complexities. Such an initial foray opens space for our investigation into how to incorporate positionality into engineering design education from its earliest stages to shape engineering thinking in students.

\section{COURSE CONTEXT}

Positionality was introduced as a foundational design tool in an approximately 300 student, first-year design course at a large, public, research-intensive university. This course was the second course in a two-course engineering design sequence, occurring in their second semester of engineering studies. The 300 students are supported by a full Teaching Team (TT) of 17 professors, instructors, and graduate teaching assistants. Instruction in the course takes the form of full-class experiential learning, active lectures, and smaller 24-person studios with two studio instructors. Our pedagogy, grounded in Vygotskyian principles, emphasizes the role of reflection to develop consciousness of one's actions and their outcomes, and to inform and guide subsequent actions [14].

To enact that consciousness, this course asks students to effect a positive change in the lived experience of a local community outside of the university, occurring in two phases. In the first phase, students explore communities they have a personal interest in or are curious about. The communities that the students identify range from privileged to vulnerable, with diverse demographic, socioeconomic and ability characteristics. As a result, students need to engage in ways that demonstrate contextual awareness and respect. Students build a "working with" relationship with their selected communities, rather than "working for" clients. With the community members as key stakeholders, students specify a design opportunity to improve the lived experience of that community (framed as engineering requirements). This working-with relationship requires the students to acknowledge how their positionality affects how they perceive, interpret, and frame situations in their communities. In Phase II, student teams develop designs to respond to these opportunities and verify and validate their work through testing and stakeholder engagement.

In previous years, students' awareness of perspectives has been supported through values identification exercises on two levels - personal and engineering design values (e.g. using DfXs) - and in two contexts - individual and team. The students produced a range of products - an individual and team profile, a set of field notes observing a community-however, the TT was dissatisfied. With some wonderful exceptions, the students produced lists of skills and experiences without integrating a deeper understanding of how their own role and understanding shaped their teams and community experiences.

Positionality was seen as having potential to meet the course learning objective of helping students become more aware of perspectives besides their own. Positionality in particular prompts students to develop increased awareness of how their past experiences, beliefs, and values might influence how they engage with communities they have not previously experienced. As a result, we chose to embed positionality as a touchstone throughout the course, appearing in lectures, studios, and assignments for both teams and individuals.

\section{TEACHING TEAM DEFINITION OF POSITIONALITY}

On principle, the TT models the processes and concepts being taught as it designs and implements the course. Therefore, assignment design is accomplished through a consultative, iterative process with engagement from a broad range of course stakeholders. Assignment refinement moves out from the core instructors to the full TT. The TT does not ask students to work on activities, or in ways, that we would not. The sharing of personal experiences and practices, as well as the modelling of the behaviours and practices we ask of our students, are fundamental to our teaching philosophy.

The course already emphasizes the explicit inclusion of identity and values (part of positionality) partially because our conceptualization of design prioritizes working with and understanding stakeholders. However, positionality offered more explicit language and focus. At the same time, positionality had the potential to disrupt the supportive learning space the team works to create, so our modelling works to encourage students to take learning risks.

In considering the value, risks and costs of integrating positionality into assignments for our students, it became clear that we did not share a common understanding of or assumptions about positionality. Was it the same as a worldview? What, if any, individual agency did one have in determining and identifying positionality? How much did the TT want to deal with gender, race, sexuality, class privilege, and power? Were the students mature enough to perceive a different perspective from their own? Would we be able to support them in recognizing their own values and most importantly how those were reflected in the interpretations of others' behaviours, judgments, decisions and actions?

This discussion began in the fall with the paper authors first sharing a statement of their own expectations of the course as one instantiation of their own positions. We articulated our positions which began multiple discussions of exactly what positionality means to us in this context. 
As a result, we decided to approach positionality with respect to engineering design in order to ground students to a fixed orientation point instead of society at large. The TT intended to ensure that the way students were exploring and articulating their identity was appropriate to the context of an engineering design course.

The value of the creating a position statement became clear as the full TT went through the process of identifying their own positionality. The TT gained an awareness of the value of such a statement as they reflected on, and elicited their own positionality, how it affected their values in design, approach to a design process, who they chose to work with, and how they worked on team projects. This gave us confidence that identifying positionality would provide a practical and meaningful way to integrate the identity and value elements of the curriculum with a design process.

\section{POSITION STATEMENT ASSIGNMENT}

Prior to our students joining our course, many had developed a résumé as part of either their high school education or securing employment. All of our students had presented themselves to our faculty's Admissions Committee as being exceptional candidates. As such, we took as a given that our students were practiced at creating outward-facing, accomplishment-focused articulations of themselves. For the position statement assignment, we wanted each student to develop a more inward-facing articulation that went beyond the content in a résumé and cover letter.

In designing the new position statement assignment, we were concerned about student readiness to engage with the subject and the possible risks to more vulnerable students. We agreed that a position statement should articulate at least what a student considered important, what influenced them, and how they oriented themselves toward engineering and design. Critically, the TT agreed that positionality is not fixed; rather, it evolves as an individual encounters new experiences and learns both within their first-year design course and beyond. The Position Statement Assignment, therefore, would be framed to students as a first articulation, with the goal of laying the groundwork to develop an awareness of and build skills for reflective thinking and intentionality in engineering design activities moving forward.

\subsection{Crafting the Assignment}

For the position statement assignment, we asked if it was possible to capture the utility of the professional communication of the former individual and team profile documents, while facilitating the expression of the unique perspective of the students, combined with some preliminary reflection on how this may interact with their design work.
In writing the Position Statement assignment, we focused on three areas:

- Providing a clear definition of positionality, along with its connection to engineering design

- Encouraging reflection on the connection between one's positionality and their past engineering design experiences as well as their upcoming engineering design work

- Maintaining the workload for the weighting of the assignment (3\% of final grade)

In developing the assignment parameters, we considered whether we should keep the assignment as a written document, or let students choose a format of expression that best represented them. We were interested in whether the flexibility would allow students to express themselves in a clear and authentic manner, and whether students would take up that opportunity. We recognized that the use of multiple semiotic forms affords opportunities to expand the expressive boundaries of language, while also inviting expression in forms the students may find to be a better reflection of themselves. However, the TT expressed concerns that if the piece submitted was difficult to interpret, very abstract, or in a format we were not familiar with analyzing, it might disadvantage students who chose to take the risk. We considered asking students to include a written statement on how to interpret their Position Statement if they chose a different medium. However, we considered this would stifle expression by effectively maintaining the written document only format. In order to limit assessor bias in interpretation, we required the verbal expression (in any form, across any medium) of the student's position.

We developed the following assignment learning objectives for students:

1) To reflect on your experiences, learning(s) and understanding(s) of who you are at this time and where you stand in relation to what you understand to be engineering, design, and the context in which those are practiced.

2) To relate your academic and personal experiences in a way that articulates who you are and how this informs your perception and interpretation.

3) To make conscious decisions about form and content as an expression of yourself for a specific purpose, resulting in a coherent representation.

4) To create a statement that shows who you are as a student engineer and the values you bring to your engineering design work at this point in your development. 
In the final assignment description, we explicitly stated the following prompts to focus students on specific content to use in their position statement:

- Who you understand yourself to be at this point

- Your beliefs about engineering, design, and engineering design, and why you want to engage in this kind of work

- The values you bring to your practice of the above, and how they are shown in your work

- How your experiences inform both what you perceive and how you interpret it when engaging in engineering design

\subsection{Planning for Assessing the Assignment}

We wanted to both uphold our established practices around rigour and clarity in assessment while also facilitating a psychologically-safe space for students to take risks as they articulated their beliefs and values. So, we needed to avoid assessor bias and preference towards a set of beliefs and values, or type of expression. We also needed to ensure in communicating our evaluations that students would not perceive that their personalities, values, or experiences were being assessed. At the same time, we needed to ensure that the full TT was comfortable assessing the aspects of identity that students chose to voice. We focused on the following criteria for assessment:

1) The quality of the description of the individual and their position(s), including:

- whether the statement provided a portrait of the individual and shared more information than a résumé;

- the quality with which the statement connected who they are now and how they have and hope to practice engineering design.

2) The quality of the relationship between form, content, and desired outcome of the statement, by:

- focusing on communication aspects, such as the effectiveness of the organization and presentation in making the statement's meaning clear and easy to interpret;

- $\quad$ considering whether the structure of the statement represented at least some of the values expressed in the content.

When assessing, members of the TT were encouraged to pass any position statements that they either felt concerned about assessing or uncomfortable assessing to the instructor group. Additionally, a member of the instructor group cross-calibrated TT feedback to students on their assignments and ensured through select sampling that assessors were meeting the assessment objectives.

\section{POSITIONALITY IN LECTURE}

Positionality was incorporated in lectures in three ways:

1) Introducing and modelling the positionalities of the course instructor group,

2) Sharing models and frameworks to enable incorporation of positionality in design practice,

3) Exploring positionality in engineering designs that exist in the world around us.

In the first few lectures of the course, each of the four named professors introduced who we are to the class by sharing an introduction slide composed only of images that represent the components of our identities. We each chose what to include and exclude and how we told the story of the images. After each instructor had shared their self with the class, we put up all four slides simultaneously to not only explore how we had each articulated who we are, but also to discuss the values and beliefs that informed our sense of self and image choices. Doing this in a collegial compare-and-contrast approach with all four professors allowed us to model how individuals' past experiences and values influence how we see the world, and also that sharing who we are enables others to better appreciate how we engage with the world. Additionally, some instructors shared their personal teaching philosophy or positionality components of past research work to show ways in which positionality is embedded in practice. Through respectfully asking each other how our identities position us in engineering, design, and teaching, we were able to model how to explore positions and how they afford or limit different ways of seeing the world.

Models were used to provide structure and vocabulary for students to explore the ways individuals understand and engage with situations differently. Three models proved particularly important.

1) Perceive $\rightarrow$ Interpret $\rightarrow$ Assess $\rightarrow$ Act. This model asks students to not jump to assumptions and act before considering how their positionality affects how they interpret a situation. We chose to use the language perceive as the word 'observe' was ableist towards those might have visual limitations. This model allowed us to explore multiple ways of interpreting situations around us and leveraging the diverging and converging tools of design to explore possible interpretations and assess which might be most appropriate before acting.

2) Claude Shannon's Encoding Decoding Model [15]. Shannon's model shows how diversity afforded the TT and the class as a whole with opportunities to understand situations in different ways, that when combined provided a greater appreciation of the situations. 
3) Chris Argyris' Ladder of Inference [16], which shows the range of filters that an encoded message might pass through in an individual's interpretation of a communication.

Exploring positionality in engineering designs in the world offered a way to help students see its impact. For example, during the early days of the COVID-19 pandemic, the media frequently discussed the development of face shields. We used a number of those examples to explore how positionality not only affected the designs being created, but also the ways in which those designs were represented by journalists. Through this we could show students how different DfX principles (or the values the designers chose to incorporate in their designs) influenced the designs of their face shields, and approaches to producing them. Moreover, our exploration was able to uncover how those with intersectional identities (e.g. engineer + woman) were often reduced to a singular identity in the media. This allowed for a discussion of the importance of selecting ways of describing stakeholders that represents them as they see and understand themselves, rather than as we see them.

\section{POSITIONALITY IN STUDIO}

In addition to lectures, we created experiential learning for the students in a series of three studio activities. The goal was to guide the students to iteratively develop and reflect on identity, positionality, and engineering design, as well as the interplay between these three ideas. Studios are two hours long and occur once a week in classes of approximately 24 students with two instructors.

The learning objectives of the first studio were to have students begin developing a defined perspective of engineering and design that they believe in, and to start exploring their identity and beliefs while developing language to articulate this. Students completed an activity in small groups where they were asked to categorize a list of artifacts based on whether they embodied engineering or design [17]. This was followed by an individual activity where the students filled in a sheet describing their definitions of engineering, design, and engineering design, along with any personal values they resonate with in their lives and engineering education. This self-description sheet served as an early iteration of the Position Statement assignment discussed in Section 5.

The second studio focused on taking individual positionality into a team. The students met their design teams for the first time and focused on exploring the interactions between the personal values and perspectives of each member of the team through four activities. These explorations contributed to the formation of team positionality to be continuously developed and applied in upcoming team deliverables. First, students shared their positionality with their teammates, and as a team, discussed values that aligned as well as ones that potentially clashed. Second, teams identified the values they hoped to embody or express as a team in their design work. To encourage the exploration of positionality in action, we asked teams to develop and note strategies for incorporating their values into their work together for the semester. Third, the teams explored potential communities to work with whose positionality may be compatible with the team's. Finally, we introduced the Launcher project as a Build-Test activity where students would experience the first application of personal and team positionalities.

For the third studio in this series, the learning objectives were to gain experience with making observations, identify observations as separate from interpretations, and understand how biases and assumptions may inform interpretations. Here, the key was to explore positionality by building an awareness of biases, assumptions, and perceptions in interactions with and observations of communities, as the students prepared to engage with off-campus communities that they were looking to work with for their term design projects. The studio began with a class discussion to identify and distinguish observations and interpretations using a series of photographs from local events. This was followed with an individual "mock" field notes activity where students watched a video from National Geographic about a day in the life of a lighthouse keeper [18] while taking notes. Prior to playing the video, students were prompted to state their positionality by noting any past experiences with the lighthouse keeper community, and any assumptions they may have about what the video would show. In follow-up discussion, students were encouraged to share some interpretations along with how they were formed from the observation. This video was selected to challenge students' ideas of objectivity as it follows one person and contains no verbal communication or displays of emotion, and students were able to hear a variety of interpretations from the varying positionalities of their classmates. As a final activity, students were asked to identify opportunities for engineering design based on their field notes from the video, along with questions to ask the community to reduce bias and to determine the validity of the opportunity.

From the set of studio activities, students gained a deeper understanding of their own positionality, the ways in which their positionality interacted and intersected with their classmates (or more specifically their teammates), and the ways in which they could use and account for their own positionality as they interacted with other communities.

\section{SUBSEQUENT ASSIGNMENTS}

Following the course pedagogy of spaced repetition, positionality was woven into all subsequent individual and team assignments. Each assignment specified that the author or authoring team explicitly state their positionality and how it influenced the content of that deliverable. This 
requirement applied whether the assignments took the form of a written document, an oral presentation, or a demonstration where positionality was always expected to be integrated.

For teams, this requirement prompted them to explore how their individual positionalities affected how their team formed, understood, and approached their work. For both teams and individuals, having to restate and recontextualize their positionality prompted them to explore their growth and evolution during the course.

For instructors, having access to the contextualized and updated position statement allowed the TT to discuss with the students the integrity the students had between their stated positionality and their design choices in practice as a way to enhancing self-awareness in the students.

\section{UPTAKE OF POSITIONALITY BY THE CLASS}

The value of the assignment was strongly confirmed by the range of forms of the position statements and the startlingly original and thoughtful statements that students submitted. Contrary to the expectations of several TT members, 73 of 269 submissions involved something other than plain text (e.g. graphics, narration, images, etc. - see Table 1). However, even the text-only submissions were often decidedly un-résumé-like including, for example, a "Choose your own adventure", a Q \& A transcript, and a statement framed in terms of mathematical axioms. More than one student expressed thanks for the opportunity to step back and reflect about themselves, to learn about themselves.

Table 1: Counts of Student Submissions by File Type and Content

\begin{tabular}{|c|c|c|}
\hline File Type & Content & Count \\
\hline \multirow[t]{6}{*}{ PDF } & Text & 196 \\
\hline & Text + Images ${ }^{\text {a }}$ & 40 \\
\hline & Text + Graphics ${ }^{b}$ & 4 \\
\hline & Text + Images + Graphics & 7 \\
\hline & Hand-written & 1 \\
\hline & Infographic ${ }^{c}$ & 2 \\
\hline Presentation & Text + Images + Graphics & 2 \\
\hline MP3 & Audio & 5 \\
\hline MP4 & Audio-Visual & 11 \\
\hline Website & Test + Images + Graphics & 1 \\
\hline \multicolumn{3}{|c|}{$\begin{array}{l}\text { amages refers to photographs, generally of people, places } \\
\text { or things. b Graphics refers to figures or other graphica } \\
\text { representations that generally involves shapes and } \\
\text { connections. c Infographic refers to the communicative } \\
\text { genre that integrates small amounts of text with multiple } \\
\text { graphical representations to present an overview of a topic }\end{array}$} \\
\hline
\end{tabular}

Overall, the TT found the assignment easier to mark than they had anticipated. What the TT learned about the students' positions allowed them to support students' learning, particularly students whose position statements revealed that they were ill-equipped to handle the ambiguity and uncertainty that comes in a team-based, community-partnered design project. TT members found they were able to express appreciation for the insight the statements provided and respect the identities the students were articulating.

Observations in Studios, comments from students in lecture and on back channels - where some students debated the concept and the validity of including positionality as an aspect of engineering - as well as individual conversations with students all seemed to indicate that some of the students had begun to integrate their nascent understanding of positionality into their conceptualization of engineering. In Studios when TT members shared their own positionality and modelled justifying different perspectives from the same evidence, students appeared genuinely engaged in the discussions and the activities that followed. From anecdotal evidence based on Studio observations and impressions, we can claim that some teams embraced the concept. For example, one team deliberately agreed on "squirreling" as a team value and how they wanted to be identified and so approached the Launcher assignment with that as their goal. Other teams shared a value of sustainability and decided to use only materials they could recycle, while others chose to design from the perspective of always having a functional product in case other courses made demands on their time. TT members also saw teams deliberately commit to accuracy or simplicity in design.

TT members believe that more students sought out communities related to a personal interest than in previous years. The Requests for Proposal were seen to reflect team, and by extension individual, values and relationships in a deeper and more engaged way than in the past. In later course deliverables - a Beta critique and a final Detailed Design Decision or Verification-more explicit references were made to the impact of position on framing, setting requirements, and initial design decisions than in past years.

Finally, many of the students' final design handbooks provided evidence that students had chosen to re-visit and revise their position statements. Some students integrated aspects of their positionality into their Personal Engineering Design Process. Many students explicitly referenced aspects of their position statements to justify their Personal Engineering Design Process. Other students integrated aspects of their positionality into their assessments of the different Tools, Models, and Frameworks they chose to include in the Handbook.

\section{DISCUSSION QUESTIONS FOR FUTURE WORK}

The TT is convinced we have enough evidence to retain and refine the assignment: the students engaged and gained 
an outlet to express and define themselves, community engagement became more focused with deeper commitments, and the TT gained insight that facilitated teaching and supporting students in studios. However, we still have many questions, especially:

- Did positionality have the impact on the students we had hoped for?

- Were the risks associated with placing students in a potentially vulnerable situation outweighed by the benefits of the outcome?

- Could we improve the sequence of assignments and activities?

- Did the students consider what was important to them, influenced them and how that positioned them in relation to the rest of the world, specifically their engineering world?

- Did they understand that their positionality will continue to develop and change?

- Did they understand that they, the students, have agency in this process?

- What impact did conscious awareness of position have on their understanding and practice of engineering?

- Can we claim that acknowledging and understanding one's own position can contribute to the development of empathy and reflexivity?

Answers to these questions require further work through systematic analysis of the texts students and student teams produced, and individual, team, and TT interviews. To that end, the next step involves collecting data on the impact of this instruction and analyzing it using a concurrent mixedmethods approach of embedded research design. Quantitative and qualitative data will be collected periodically throughout the term with students who opt into this more in-depth study. These will include the collection and analysis of assignments, observations, and interviews with students and TT members. Future work will also include examining methods of integration of positionality into engineering design activities and deliverables as a means of promoting empathy and reflexivity in student design practice. This research will also explore how positionality influences students' understandings of their agency as engineers, and the impact that understanding has on the framing and stakeholder engagement aspects of their design activities.

\section{Acknowledgements}

Conclusions and learnings were not gained through research (for wide external application) but through a QI/QA project carried out in the local context.

\section{References}

[1] P. T. Robbins, "The reflexive engineer: perceptions of integrated development," Journal of International Development, vol. 19, pp. 99-110, 2007.

[2] J. Walther, S. E. Miller and N. W. Sochacka, "A Model of Empathy in Engineering as a Core Skill, Practice Orientation, and Professional Way of Being," Journal of Engineering Education, vol. 106, pp. 123-148, 2017.

[3] N. Sakellariou, "'The X-Engineer": Engineering Reflexivity and Identity Formation [Opinion]," IEEE Technology and Society Magazine, vol. 32, no. 1, pp. 2527, 2013.

[4] L. Alcoff, "Cultural Feminism versus Post-Structuralism: The Identity Crisis in Feminist Theory," Signs, vol. 13, no. 3, pp. 405-436, 1988.

[5] D. Takacs, "Positionality, Epistemology, and Social Justice in the Classroom," Social Justice, vol. 29, no. 4, pp. 168-181, 2002.

[6] K. V. L. England, "Getting Personal: Reflexivity, Positionality, and Feminist Research," The Professional Geographer, vol. 46, no. 1, pp. 80-89, 1994.

[7] G. Rose, "Situating knowledges: positionality, reflexivities and other tactics," Progress in Human Geography, vol. 21, no. 3, pp. 305-320, 1997.

[8] S. M. Acevedo, M. Aho, E. Cela, J.-C. Chao, I. GarciaGonzales, A. MacLeod, C. Moutray and C. Olague, "Postitionality as Knowledge: From Pedagogy to Praxis," Integral Review, vol. 11, no. 1, pp. 28-46, 2015.

[9] A. Kezar, "Reconstructing Static Images of Leadership: An Application of Positionality Theory," Journal of Leadership Studies, vol. 8, no. 3, pp. 94-109, 2002.

[10] H. R. Milner, "Race, Culture, and Researcher Positionality: Working Through Dangers Seen, Unseen, and Unforeseen," Educational Researcher, vol. 36, no. 7, pp. 388-400, 2007.

[11] A. Kirn, A. Godwin, C. Cass, M. S. Ross and J. L. Huff, "Mindful Methodology: A transparent dialogue on Adapting Interpretative Phenomenological Analysis for Engineering Education Research," in American Society for Engineering Education Annual Conference and Exposition, Columbus, OH, 2017.

[12] M. Chung Hearn, "Positionality, Intersectionality, and Power: Socially Locating the Higher Education Teacher in Multicultural Education," Multicultural Education Review, vol. 4, no. 2, pp. 38-59, 2012.

[13] C. V. Cedillo and P. Bratta, "Relating our experiences: The practice of positionality stories in student-centered pedagogy," College Composition and Communication, vol. 71, no. 2, pp. 215-240, 2019.

[14] L. Vygotsky, Thought and Language, Cambridge, MA: MIT Press, 1986, pp. 170-171.

[15] C. E. Shannon, "A Mathematical Theory of Communication," The Bell System Technical Journal, vol. 27, pp. 379-423,623-656, 1948. 
[16] C. Argyris, Overcoming Organizational Defeses: Facilitating Organizational Learning, Boston: Allyn and Bacon, 1990.

[17] A. Chong, J. Foster and P. K. Sheridan, "Define "Engineering Design": Understanding how freshman students develop their understanding of engineering, design, and engineering design," in American Society for Engineering Education Annual Conference and Exposition, Atlanta, GA, 2013.
[18] I. Clark, Director, They are the last. [Film]. Spain: Kauri Multimedia, 2013 